\title{
Airflow Acoustic Research on Mandarin Voiceless Fricatives Yonghong $\mathrm{Li}^{1}$
}

\author{
${ }^{1}$ Key Lab of China's National Linguistic Information Technology, Northwest University for \\ Nationalities, Lanzhou, 730030, China
}

Keywords: fricatives, aerodynamics, airflow ratio, air pressure, PAS6600

\begin{abstract}
Taking Chinese mandarin voiceless fricatives as its research objects, this paper has collected the airflow signals from 20 speakers (10 males and 10 females) with PAS6600 to collect the speech, airflow and air-pressure signals, studying on the Peak Air Pressure (PAP), Peak Expiratory Airflow(PEA), Expiratory Volume(EV) of the Chinese mandarin voiceless fricatives. Among the fricatives, [f], [s], [x] and [sh], their AP values are higher because of their voiced degrees. But $[\mathrm{h}]$ its PEA and EV values are higher because of its lower voiced degree.
\end{abstract}

\section{Introduction}

Breath is considered as 'the motive force' for sound generation. No breath means there is no voice source. Focusing on studying the air-pressure and airflow during speech producing process is known as the voice of aerodynamics[1]. Isshiki,N. and Ringel,R studied the airflow during the production of selected consonants(1964) [2]. Catford had devoted to the pressure, airflow rate and airflow pattern in sound track(1977)[3]. Rothenberg did the measurement of speech airflow(1977)[4]. Shadle studied an articulatory-acoustic-aerodynamic analysis of [s] in VCV sequences(1995). His compiled the aerodynamics of speech recorded into the Handbook of Phonetic Sciences [5]. Ladefoged,P. edited Aerodynamic Investigations: Phonetic Data Analysis(2003)[6].

In 1980s, when the airflow and air-pressure used for speech studying method had been brought into China, Mr. Wu Zongji was the first to do the experiment at the terms of the unaspirated/aspirated distinguishing features among Chinese mandarin consonants[7]. Cun Xi used PAS6600 for the phonetics characteristics of implosives in two Chinese dialects between Wuyang and Wenchang(2009)[8].

This paper has taken the Chinese mandarin voiceless fricatives as its research subjects, using Phonatory Aerodynamic System 6600 from American KAY Company to study the PAP, PEA, EV these features of Chinese mandarin voiceless fricatives.

\section{Research methods}

The fricatives, differing from stops, can be lasting initials. During the articulating process, some part of the track can shrink and the airflow flow fast from the lung because of the lung pressure, thus the airflow form the turbulence at the slit of shrinking part to produce the noise source. After the resonance effect of the track, the noise source generates the fricatives. The physiological features of the fricatives are very complicated with different articulating places. And their articulating methods are also some different, showing disordered stripes in acoustic speech spectrogram.

Selecting five voiceless fricatives $[\mathrm{f}(\mathrm{f})] /[\mathrm{s}(\mathrm{s})] /[\mathrm{sh}(\mathrm{s})] /[\mathrm{x}(\mathrm{c})] /[\mathrm{h}(\mathrm{x})]$ and vowels $[\mathrm{a}] /[\mathrm{u}] /[\mathrm{i}] /[\mathrm{e}]$ matching each other together, total 20 syllables, all with the first tone 55 . The speakers in this experiment include 10 males and 10 females, aged between 20 and 35 years old, being students at university with standard mandarin. And they voice pure and smooth aspiration, with no language and hearing impairment or voice disease history. The sampling rate is $16 \mathrm{kHz}$. Figure 1 to Figure 5 are the airflow and air pressure signals for [fa], [sa], [sha], [xia] and [ha], where there are 4 channels. The 1st channel is Pitch channel, unit Hz. The 2nd channel is Sound Pressure Level (SPL), unit dB. 
The 3rd channel shows the airflow signal (AF), unit Lit/Se and the 4th channel Air pressure, unit cmH2O.

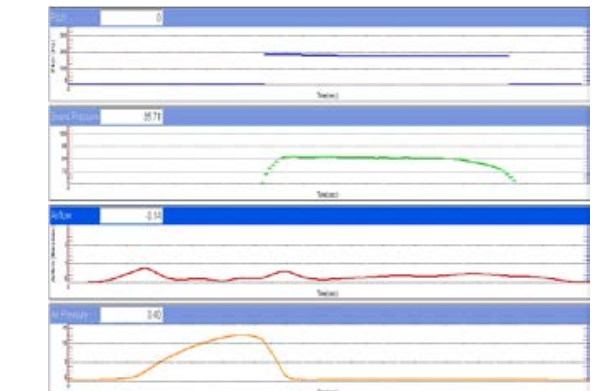

Fig.1: [fa]

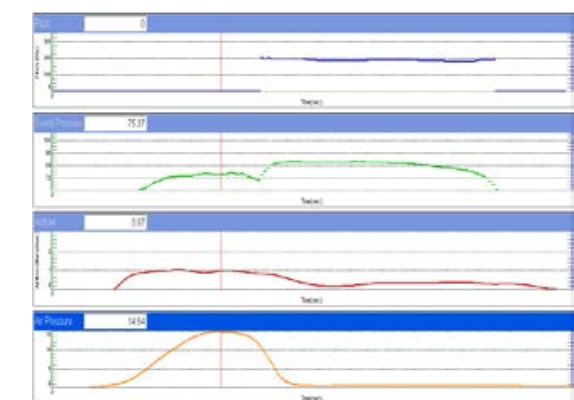

Fig.3: [sha]

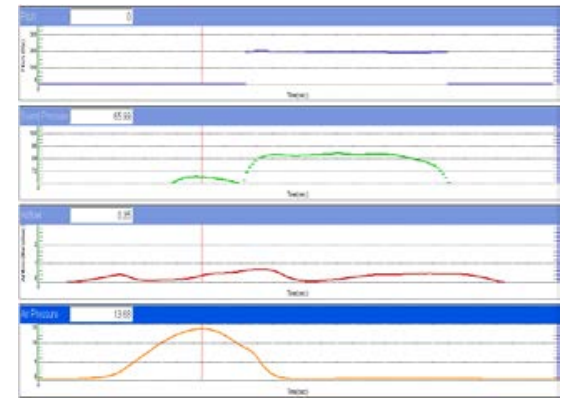

Fig.2: [sa]

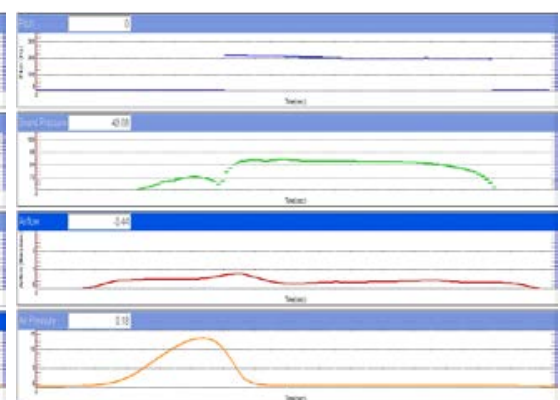

Fig.4: [xia]

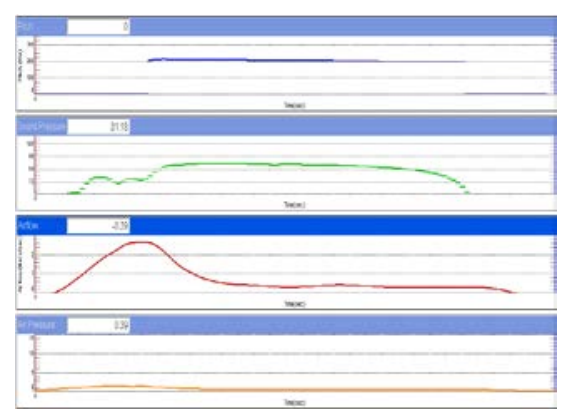

Fig.5: [ha]

As a whole, when speakers articulate voiceless fricatives, the air pressure signal and airflow signal rise from the zero at the initial position, and reach the steady state quickly, keeping at 50-70 $\mathrm{dB}$. Besides [h], the airflow ratio of the other fricatives keeps at $0.2-0.8 \mathrm{~L} / \mathrm{S}$, with some fluctuation. And the air pressure signal rises slowly to the maximize value $12 \mathrm{cmH}_{2} \mathrm{O}$, and then start to decline slowly. The air pressure value of $[\mathrm{h}]$ is the lowest but the airflow ratio is the highest.

\section{Peak Air Pressure}

Air pressure means the air power do efforts on some unit area, unit $\mathrm{cm}_{2} \mathrm{O}$. In phonetics, the tested oral pressure is the overpressure, which has deduct the standard atmospheric pressure, unit $\mathrm{p}$, commonly used unit for $\mathrm{cm}$ water column $\left(\mathrm{cmH}_{2} \mathrm{O}\right)$. In natural languages, people's oral air pressure range is $3 \mathrm{cmH}_{2} \mathrm{O}-15 \mathrm{~cm} \mathrm{H}_{2} \mathrm{O}$. The formula for PAP as follows:

$$
\left.\mathrm{p}=(\mathrm{u} / 412)^{2} \quad \text { (from Experimental Phonetics Summary [1] }\right)
$$

Where u means the moving speed of air particles, $\mathrm{p}$ unit $\mathrm{mmH}_{2} \mathrm{O}$, could be converted into $\mathrm{cmH}_{2} \mathrm{O}$. PAP means the peak value in consonant articulation process here.

Air pressure is an important parameter of the consonants, different consonant different oral cavity pressure. During the articulation, the air pressure changes all the time. To some extent, the Peak Air Pressure (PAP, unit $\mathrm{cmH}_{2} \mathrm{O}$ ) largely determines the nature of the consonant. Fricative's PAP generally appears the first $2 / 3$ position of the fricative section. We calculated the air pressure 
values from the male and female speaker groups separately, and detailed results show in Table 1 and Table 2.

Table 1: Voiceless fricatives PAP results of male $\left(\mathrm{cmH}_{2} \mathrm{O}\right)$

\begin{tabular}{cccccc}
\hline TITLE & {$[\mathrm{f}]$} & {$[\mathrm{s}]$} & {$[\mathrm{sh}]$} & {$[\mathrm{x}]$} & {$[\mathrm{h}]$} \\
\hline Max & 14.52 & 16.46 & 16.82 & 17.61 & 2.79 \\
Min & 8.18 & 8.41 & 10.57 & 8.35 & 0.8 \\
Mean & 12.14 & 12.88 & 14.77 & 12.93 & 1.5 \\
\hline
\end{tabular}

Table 2: Voiceless fricatives PAP results of female $\left(\mathrm{cmH}_{2} \mathrm{O}\right)$

\begin{tabular}{cccccc}
\hline TITLE & {$[\mathrm{f}]$} & {$[\mathrm{s}]$} & {$[\mathrm{sh}]$} & {$[\mathrm{x}]$} & {$[\mathrm{h}]$} \\
\hline Max & 19.49 & 17.85 & 17.29 & 18.16 & 2.79 \\
Min & 11.16 & 10.74 & 10.33 & 9.84 & 0.48 \\
Mean & 14.12 & 13.54 & 13.51 & 12.7 & 0.74 \\
\hline
\end{tabular}

As can be seen from Table 1 and Table 2, The initial [f], [s], [x] and [sh], their PAP values are larger for their obstructed degree higher in articulating places, but [h] its PAP value is very small.

\section{Peak Expiratory Airflow}

Airflow signal means the maximize value during the airflow velocity changes over time. Airflow velocity uses $U$ as its symbol, means the product of air particles' speed and cross-sectional area A in certain time. The formula for airflow velocity:

$\mathrm{U}=\mathrm{u} * \mathrm{~A}$ (from Experimental Phonetics Summary[1])

Considering the articulating places obstructed in different ways, different fricatives have different airflow rates. The Peak Expiratory Airflow (PEA) mainly tests the airflow in passing through the track producing the largest airflow rate. Airflow rate is proportional to the area of the articulating organs touching together and the air pressure value. The larger the area, the greater the airflow volume passing through the area by unit time; so the larger air pressure and also the airflow rate of the unit area. Comparing with other consonants, the longer the fricative, the smaller the airflow rate, and the PAP is about $0.54 \mathrm{~L} / \mathrm{s} \sim 1.97 \mathrm{~L} / \mathrm{s}$. Table 3 and Table 4 show the PAP values of voiceless fricatives.

Table 3: Peak Expiratory Airflow of male (L/s)

\begin{tabular}{cccccc}
\hline TITLE & {$[\mathrm{f}]$} & {$[\mathrm{s}]$} & {$[\mathrm{sh}]$} & {$[\mathrm{x}]$} & {$[\mathrm{h}]$} \\
\hline Max & 1.3 & 1.32 & 1.25 & 1.78 & 2.83 \\
Min & 0.43 & 0.53 & 0.63 & 0.84 & 1.83 \\
Mean & 0.73 & 0.77 & 1.01 & 1.06 & 2.31 \\
\hline
\end{tabular}

Table 4: Peak Expiratory Airflow of female (L/s)

\begin{tabular}{cccccc}
\hline TITLE & {$[\mathrm{f}]$} & {$[\mathrm{s}]$} & {$[\mathrm{sh}]$} & {$[\mathrm{x}]$} & {$[\mathrm{h}]$} \\
\hline Max & 1.0 & 0.72 & 1.23 & 0.82 & 2.40 \\
Min & 0.5 & 0.21 & 0.36 & 0.34 & 1.82 \\
Mean & 0.66 & 0.44 & 0.79 & 0.64 & 2.11 \\
\hline
\end{tabular}

From Table 3 and Table 4 we can see that: male speakers' PEA values are larger than the females'. Besides [h], the other four fricatives' PAP mean airflow values are all smaller than 1 . The PAP value of $[\mathrm{h}]$ is 2-3 times of other fricatives, which is mainly because the initial $\mathrm{h}$ is velar soft palate fricative and the obstructed degree is the smallest. 


\section{Expiratory Volume}

Expiratory Volume (EV, Unit L) means the amount of exhaled airflow in consonant articulation process. First, using the integration for the airflow signal in EAD, this is the area for airflow signal and the time coordinate axis. The formula for EV and Table 5 and Table 6 show the EV values of the voiceless fricatives:

$$
\mathrm{EV}=\int_{\mathrm{st}}^{\mathrm{et}} \text { AF (from Experimental Phonetics Summary[1]) }
$$

Table 5: Voiceless fricatives EV values of male (L)

\begin{tabular}{cccccc}
\hline TITLE & {$[\mathrm{f}]$} & {$[\mathrm{s}]$} & {$[\mathrm{sh}]$} & {$[\mathrm{x}]$} & {$[\mathrm{h}]$} \\
\hline Max & 0.10 & 0.12 & 0.22 & 0.12 & 0.28 \\
Min & 0.05 & 0.06 & 0.16 & 0.08 & 0.15 \\
Mean & 0.07 & 0.08 & 0.18 & 0.10 & 0.18 \\
\hline
\end{tabular}

Table 6: Voiceless fricatives EV values of female (L)

\begin{tabular}{cccccc}
\hline TITLE & {$[\mathrm{f}]$} & {$[\mathrm{s}]$} & {$[\mathrm{sh}]$} & {$[\mathrm{x}]$} & {$[\mathrm{h}]$} \\
\hline Max & 0.09 & 0.15 & 0.19 & 0.13 & 0.31 \\
Min & 0.03 & 0.05 & 0.09 & 0.06 & 0.15 \\
Mean & 0.06 & 0.10 & 0.15 & 0.09 & 0.22 \\
\hline
\end{tabular}

Generally speaking, the longer the articulating time, the larger the expiratory volume. Comparing with other consonants, fricatives have long articulating duration with larger expiratory volumes. While male speakers' EV values are similarly larger than female speakers'. The EV relationship of the voiceless fricatives: [f] $<[\mathrm{s}]<[\mathrm{x}]<[\mathrm{sh}]<[\mathrm{h}]$.

\section{Conclusions}

The articulating places of the initials determine the area of the initial cavity, while the articulating methods determine the forms of the airflow. This paper analysed the articulating mechanism and aerodynamic features of the Chinese mandarin fricatives. These five initials have the same articulating method but with different articulating places. Among all the fricatives, [f], [s], $[\mathrm{x}]$ and [sh] their obstructed degrees are higher, so the PAP values are larger. But [h] its obstructed degree is lower, so it has larger PEA and EV values. Due to complicated synergistic effect from the articulating organs, different speakers have different vocal cords conditions, including the size and the length of the vocal track, the shape of tongue all directly affect the parameters of the airflow. So, if we can collect more samples from more speakers, we can get more general conclusion. In other words, the initials match different vowels, which causes the initials are affected by the vowels and the articulation process of the initials change obviously so that the data normalization and integration need scientific dealing with.

\section{Acknowledgments}

This article is subsidized by The National Natural Science Foundation of China (Grant No. 61202187)

\section{References}

[1] Wu Zongji, Lin Maocan, Experimental Phonetics Summary [M]. Higher Education Press, 1987.5

[2] Isshiki,N. Regulatory mechanisms of vocal intensity variation. Journal of Speech and Hearing Research,7, pp17-29, 1964.

[3] Catford,J.C. Fundamental Problems in Phonetics, Edinburgh University Press,1977 
[4] Rothenberg,M. Measurement of airflow in speech. Journal of Speech and Hearing Research, 20, pp.155-176, 1977.

[5] Shadle, C. The aerodynamics of speech. In Hardcastle ,W. J. and Laver,J. (eds.) The Handbook of Phonetic Sciences. Oxford: Blackwell, 1997

[6] Ladefoged, P. Aerodynamic Investigations. Phonetic Data Analysis. Oxford: Black well Publishing, 2003.

[7] Wu Zongji. Expound the distinguish features in Chinese mandarin initials and their inner relationship. Chinese Language, 1980.5

[8] CUN, Xi. A Phonetic Study on Implosives in China. Dphil Thesis of The Hong Kong University of Science and Technology, 2009 